\title{
Isolation and Haploidization of Heterozygous Diploid Strains in a Species of Humicola
}

\author{
By M. DE BERTOLDI* AND C. E. CATEN \\ Department of Genetics, \\ University of Birmingham, Birmingham BI5 $2 T T$
}

(Received 10 March 1975)

\begin{abstract}
SUMMARY
Stable auxotrophic mutants were induced in Humicola sp. strain 20-3I by irradiation with far ultraviolet light. Mixed inoculation of different auxotrophs on to minimal medium agar produced prototrophic mycelia in all seven combinations tested with a frequency of 0.5 to $2.5 \%$. These prototrophic mycelia were stable when subcultured by macerated hyphae, single hyphal tips, single aleuriospores or single phialospores, and contained nuclei of approximately twice the volume of those in strain 20-31. They were more sensitive to growth inhibition by $p$-fluorophenylalanine (FPA) than 20-3I and its auxotrophic derivatives and, at concentrations of $\mathrm{I} 40$ and $\mathrm{I} 60 \mu \mathrm{g} \mathrm{FPA} / \mathrm{ml}$, gave rise to more vigorously growing sectors. The mycelia from these sectors segregated for morphological and auxotrophic markers differentiating the parent auxotrophs and contained nuclei similar in size to strain 20-3I. When reinoculated on to FPA media, these segregants showed the higher tolerance characteristic of strain 20-3I and failed to segregate further. It is concluded that in mixed culture, auxotrophic mutant derivatives of Humicola sp. strain 20-3I readily form somatic heterozygous diploids and that these are induced to haploidize by treatment with FPA. A difference in pigmentation which segregates spontaneously in strain 20-3 I is attributed to a single chromosomal gene and the six markers studied are assigned to at least four linkage groups. Parasexual genetic analysis may be of value in taxonomic studies of imperfect fungi.
\end{abstract}

\section{INTRODUCTION}

A number of strains of the genus Humicola Traaen isolated from soil were observed to be unstable, giving rise to morphological variants either as sectors or single spore isolations (de Bertoldi, Lepidi \& Nuti, 1972, 1973). An understanding of the nature and extent of this spontaneous variability was essential to the taxonomic review of the genus being conducted (de Bertoldi et al. 1972, 1973; Lepidi et al. 1972) and studies were therefore initiated to determine its genetic basis. This required the development of a system of genetic analysis in Humicola which is an Hypomycete. Genetic analysis is possible in filamentous fungi in the absence of sexual reproduction through the parasexual cycle (Pontecorvo, 1956; Pontecorvo \& Käfer, 1958; Roper, 1966) and this method has been used in several imperfect fungi, including Penicillium chrysogenum (Pontecorvo \& Sermonti, 1954), Aspergillus niger (Lhoas, I967) and Verticillium albo-atrum (Hastie, I964). We report the isolation of heterozygous diploids from mixed cultures of marked derivatives of a strain of a Humicola sp. and the subsequent haploidization of these diploids. During haploidization, segregation and reassociation of the markers was observed.

* Present address: Instituto di Microbiologia Agraria del l'Università di Pisa e Centro di Studio per la Microbiologia del Suolo del C.N.R., Pisa, Italy. 


\section{METHODS}

Strains. All strains used were derived from strain 20-3I which was isolated from soil obtained from Sardinia (de Bertoldi \& Verona, 1970). The morphological and cytological characteristics of this strain have been previously described (de Bertoldi et al. 1972; de Bertoldi, 1972). On the basis of mycelial and spore characters, strain 20-3I was referred to the genus Humicola but could not be assigned to any of the described species (de Bertoldi et al. 1972). It is included in a revision of the genus currently in progress (M. de Bertoldi and G. L. Hennebert, unpublished), when it will be formally described and identified. The original mass isolate of 20-3 I produces abundant pigmented aleuriospores making the colonies appear black. Occasionally, cultures spontaneously produce white sectors which owe their distinctive appearance to a reduced level of aleuriospore production. Likewise, if $20-3 \mathrm{I}$ is propagated by single aleuriospores or phialospores the resulting colonies fall into black and white types, designated 20-3 IB and 20-3 IW respectively.

Cultural conditions. Minimal medium (MM) was basically that used for Aspergillus nidulans (Pontecorvo et al. 1953) except that $2 \%(\mathrm{w} / \mathrm{v})$ sucrose replaced I \% (w/v) glucose as carbon source. Complete medium (CM) was prepared by the addition to I $1 \mathrm{MM}$ of $\mathrm{I} \cdot \mathrm{g}$ Difco Bacto Casamino acids, $\mathrm{I} \cdot \mathrm{O} \mathrm{g}$ Difco Bacto peptone, $\mathrm{r} \cdot \mathrm{O} \mathrm{g}$ Difco Bacto yeast extract, $0.15 \mathrm{~g}$ adenine and $20 \mathrm{ml}$ of vitamin solution (Clowes \& Hayes, I968). MM and $\mathrm{CM}$ were solidified with $\mathrm{I} \cdot 5 \%$ (w/v) agar (Oxoid No. 3) to give MMA and CMA respectively. All incubation was at $26^{\circ} \mathrm{C}$ and, except where stated, suspension and dilution of spores and mycelial fragments was carried out in $0.001 \%(\mathrm{v} / \mathrm{v})$ Tween 80 solution.

Production of spores. Strain 20-3 I produces both aleuriospores and phialospores. The former are multinucleate with an average of ten nuclei per spore while the latter are uninucleate (de Bertoldi, 1972). For aleuriospore production, hyphal fragments were inoculated into $100 \mathrm{ml}$ of liquid $2 \%(\mathrm{w} / \mathrm{v})$ malt $+2 \%(\mathrm{w} / \mathrm{v})$ yeast extract medium in $250 \mathrm{ml}$ Erlenmeyer flasks and incubated for 7 days on a rotary shaker (2 inch throw, $220 \mathrm{rev} . / \mathrm{min}$ ). Cultures were filtered through glass wool to remove mycelial fragments and the aleuriospores collected and washed by centrifugation. Phialospores could only be obtained from MMA slide cultures produced by the method of Riddel (1950). After 7 days' incubation the mycelium on the cover slip was gently washed to remove the phialospores and the resulting suspension filtered through glass wool. In this way phialospore suspensions which were free of aleuriospores and hyphal fragments were produced, although only in small quantities.

Ultraviolet irradiation. Aleuriospores were used for u.v. irradiation rather than phialospores, despite their multinucleate nature, because of the difficulty of obtaining large numbers of phialospores and their poor germination $(<\mathrm{I} \%)$. Ten $\mathrm{ml}$ of an aleuriospore suspension $\left(5 \times 10^{6} / \mathrm{ml}\right)$ in $0.1 \mathrm{M}$-phosphate buffer $\mathrm{pH} 6.0$ were transferred to a $9 \mathrm{~cm}$ diameter Petri dish containing a sterile paper clip. This was placed on a magnetic stirrer under a Hanovia Chromalite u.v. lamp (80\% output at $254 \mathrm{~nm}$ wavelength) arranged so that the lamp was $5 \mathrm{~cm}$ above the surface of the spore suspension. Samples $(0.3 \mathrm{ml})$ were collected at various time intervals up to $60 \mathrm{~min}$ and plated on to CMA.

Isolation and characterization of auxotrophic mutants. Survivors from u.v. irradiation were transferred to fresh CMA plates and replicated on to MMA. Suspected auxotrophic mutants were tested on MMA supplemented with (i) $3 \mathrm{mg}$ Casamino acids $/ \mathrm{ml}$, (ii) $2 \%$ (v/v) vitamin solution and (iii) a mixture of adenine, thymine, cytosine and guanine, each at $0.1 \mathrm{mg} / \mathrm{ml}$. According to their response to these complex supplements the mutants were then tested on MMA with single supplements at the following final concentrations: amino 
acids, $0.1 \mathrm{mg} / \mathrm{ml}$; biotin, $\mathrm{I} \mu \mathrm{g} / \mathrm{ml}$; riboflavin, $10 \mu \mathrm{g} / \mathrm{ml}$; other vitamins, $2 \mu \mathrm{g} / \mathrm{ml}$; adenine, thymine, cytosine and guanine, $0 \cdot 1 \mathrm{mg} / \mathrm{ml}$.

Mixed cultures. Four methods were used in attempting to produce prototrophic mycelia from mixed cultures of auxotrophic mutants on MMA: (A) two mutants were inoculated side by side on CMA, incubated for 3 days, and then hyphae from the interface were transferred to MMA; (B) mass hyphal inocula of two mutants were placed side by side on MMA and macerated together with glass needles; $(C)$ mycelia from two mutants were macerated in Tween 80, mixed, and the mixture plated on MMA; (D) aleuriospore suspensions of two mutants were mixed in CM, incubated overnight, and then $0.1 \mathrm{ml}$ portions plated on to MMA. With all four methods the mixed inocula were incubated for up to I5 days and examined periodically.

Treatment with p-fluorophenylalanine. A $0.1 \%(\mathrm{w} / \mathrm{v})$ solution of $p$-fluorophenylalanine (FPA), prepared by the method of Day \& Jones (I969), was added to CMA to give final concentrations of $60,80,100,120,140$ and $160 \mu \mathrm{g} / \mathrm{ml}$. The wild-type $20-31$, its auxotrophic mutants and the derived prototrophic strains were point-inoculated in replicate on to these FPA media and incubated for Io days. Vigorously growing sectors arising from the prototrophic strains at FPA concentrations of 140 and $\mathrm{I} 60 \mu \mathrm{g} / \mathrm{ml}$ were isolated and scored for auxotrophic and morphological markers. Not more than one sector was isolated from any single colony.

Determination of nuclear size. Strains were grown in slide cultures (Riddel, I950) for 5 days, after which mycelia and spores adhering to the coverslips were fixed in aceticalcohol $(\mathrm{I}: 3, \mathrm{v} / \mathrm{v})$ for $\mathrm{Io}$ min and stained with Giemsa following the method of Robinow $\&$ Caten (I969). Suitably stained phialospore chains were photographed and the diameters of 20 phialospore nuclei were measured for each strain from prints $(\times 8000$ final magnification) using calipers.

\section{RESULTS}

\section{Induction of mutants}

The dose-response relationship for the lethal effect of u.v. irradiation on aleuriospores of strain 20-3I (Fig. I) clearly possesses the shoulder expected with multinucleate spores (Atwood \& Norman, I949). Up to Io min exposure, no reduction in spore viability was observed. After Io min, survival decreased linearly on a logarithmic scale, falling to approximately I \% after $50 \mathrm{~min}$. The segregation of single aleuriospore cultures of 20-3 I into black and white colony types was apparent among the survivors of u.v. irradiation. The proportion of white cultures increased with increasing dose, suggesting that potentially 'white' aleuriospores were more resistant. This relationship will be considered in detail in a subsequent publication.

Altogether, 450 black and 450 white survivors were sampled from the $45 \mathrm{~min}(2.3 \%$ survival) and $60 \mathrm{~min}(0.5 \%$ survival) treatments and tested for nutritional requirements. Four non-leaky auxotrophic mutants were found (Table I). Aleuriospores from a black (20-3IB) and a white (20-3IW) segregant were similarly treated and from 300 survivors of each only one further auxotroph was recovered (Table I). All five of these auxotrophic mutants were stable, no prototrophic revertants being recovered among $1 \cdot 5 \times 10^{7}$ aleuriospores of each plated on MMA.

\section{Mixed cultures of auxotrophs}

Vigorously growing colonies arose on MMA from mixed cultures of the auxotrophic mutants established by methods B, C and D, but not by method A. No such prototrophic 


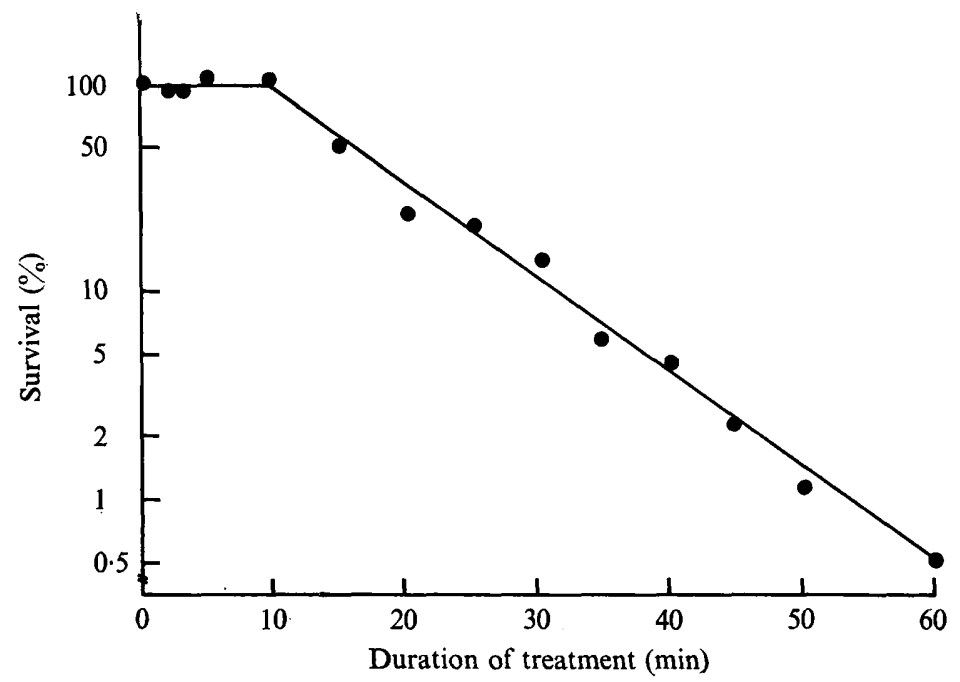

Fig. I. Lethal effect of u.v. irradiation $(254 \mathrm{~nm})$ on aleuriospores of Humicola sp. strain 20-3I.

Table I. Characteristics of auxotrophic mutants induced in Humicola strains 20-3I and 20-3 I W by u.v. irradiation

\begin{tabular}{ccccc} 
Mutant no. & Colour & Nutritional requirement & \multicolumn{1}{c}{ Genotype } & Parent strain \\
M4 & Black & Lysine & whi+lysA4 & 20-3I \\
MI6 & Black & Pyridoxine & whi+pdxAI6 & $20-31$ \\
MI7 & White & Arginine & whiAI argA17 & $20-3$ I \\
MI8 & White & Methionine & whiAI metAI8 & $20-31$ \\
MII & White & Pyridoxine & whiAI pdx-II & $20-3$ IW
\end{tabular}

colonies arose in comparable inoculations of the mutant strains singly on to MMA. Altogether, seven different combinations of the five mutants were tested (Table 2) and prototrophs were recovered in each. Quantification of the frequency of prototroph formation was difficult except with method B, where after I5 days' incubation from 0.5 to $2.5 \%$ of mixed cultures had given rise to vigorously growing mycelia, depending upon the particular combination (Table 2). A stock culture of the prototrophic mycelium from each combination was established by single hyphal tip transfer. These cultures will be referred to as the prototrophic strains and were used for all subsequent studies.

All prototrophic strains produced from a combination of a black and a white auxotroph were black. Combinations MI $7+$ MI 8 and M4+mI6, which involved two white and two black auxotrophs respectively, gave white and black prototrophs respectively. The rate of increase in colony diameter on MMA of the prototrophic strains ranged from 56 to I I I \% of that of wild-type 20-3I, depending upon the particular combination. The component mutants grown singly failed to grow at all on MMA (Table 2). The variation in growth rate among the combinations is significant, reflecting differential pleiotropic effects of the mutations on growth. 
Table 2. Frequency of prototrophic strains arising from mixed culture of auxotrophic mutants of Humicola strain 20-3 I and the increase in colony diameter on MMA of these prototrophs and their parents

Mass hyphal inocula of two mutants were placed side by side on MMA and macerated together with glass needles (method B). The increases in colony diameter shown are the means of three replicates of each strain.

\begin{tabular}{|c|c|c|}
\hline Strains & $\begin{array}{l}\text { Percentage of cultures } \\
\text { giving prototrophs* }\end{array}$ & $\begin{array}{l}\text { Increase in } \\
\text { diameter }(\mathrm{m}\end{array}$ \\
\hline \multicolumn{3}{|l|}{ Controls } \\
\hline 20-3 I & 100 & $3 \cdot 6$ \\
\hline M4 & 0 & 0 \\
\hline MII & 0 & 0 \\
\hline MI6 & 0 & 0 \\
\hline MI 7 & 0 & 0 \\
\hline MI 8 & 0 & 0 \\
\hline \multicolumn{3}{|c|}{ Mixed cultures } \\
\hline M4 + M I I & $2 \cdot 5$ & $3 \cdot I$ \\
\hline$M 4+M I 6$ & $1 \cdot 5$ & $3 \cdot I$ \\
\hline$M 4+M 17$ & $1 \cdot 0$ & $2 \cdot 9$ \\
\hline $\mathrm{M} 4+\mathrm{M} 18$ & $I \cdot O$ & $2 \cdot I$ \\
\hline MI6+MI 7 & $I \cdot O$ & 4.0 \\
\hline MI6+MI 8 & 0.5 & $3 \cdot I$ \\
\hline$M I 7+M I 8$ & 0.5 & $2 \cdot 0$ \\
\hline
\end{tabular}

* Two hundred cultures tested in each case.

\section{Propagation of prototrophic strains}

Initially it was suspected that the prototrophic mycelia arising from the mixed cultures were heterokaryons. To test this they were propagated on to CMA by macerated hyphae, single hyphal tips, single aleuriospores and single phialospores, and the resultant cultures tested for growth on MMA and on MMA with appropriate supplements. Heterokaryons should be resolved into their component homokaryons by these treatments with a frequency related to the method of propagation, being highest (100\%) for the uninucleate phialospores and lowest for hyphal tips and macerated hyphae. Segregation of the parental markers was not observed, however, and all subcultures retained both the nutritional and colour characteristics of the prototrophic strain from which they were derived, irrespective of the method of propagation (Table 3 ).

\section{Spore and nuclear size of prototrophic strains}

The stability of the prototrophic strains suggested that they might be diploids rather than heterokaryons. Spore size has frequently been used to distinguish diploid from haploid strains (see Tinline \& MacNeil, I969, for review). Aleuriospores of the present strains were very variable in size and no differences were apparent between any strains. Similarly, phialospores proved to be variable and, although on average those from the prototrophic strains were larger than those from strain 20-3I or its auxotrophic derivatives (Fig. 2), there was considerable overlap. Clutterbuck \& Roper (I966) showed that haploid and diploid strains of Aspergillus nidulans differed in nuclear size. Measurements of nuclear size were made on phialospores from the prototrophic strains and the wild-type strains 20-3 I, 20-3 I W and 20-3 I B. Phialospores were selected because their nuclei are more regular in shape than hyphal nuclei while those of aleuriospores are difficult to stain through the thick spore wall (de Bertoldi, 1972). Nuclear diameters of the seven prototrophic strains 
Table 3. Nutritional characteristics of subcultures established by four different methods of propagation of prototrophic strains formed by mixed culture of auxotrophic mutants of Humicola strain 20-3 I

Subcultures were established on CMA by plating macerated hyphae, single aleuriospores or single phialospores and by single hyphal tip transfers, and tested for their nutritional requirements by transfer to MMA and MMA with appropriate supplements.

\begin{tabular}{|c|c|c|c|}
\hline \multirow{2}{*}{$\begin{array}{l}\text { Subcultures } \\
\text { established by: }\end{array}$} & \multirow{2}{*}{$\begin{array}{c}\text { No. of } \\
\text { prototrophic } \\
\text { strains tested }\end{array}$} & \multicolumn{2}{|c|}{ No. of subcultures* } \\
\hline & & Prototrophic & Auxotrophic \\
\hline Macerated hyphae & 4 & 200 & 0 \\
\hline Single hyphal tips & 7 & 350 & 0 \\
\hline Single aleuriospores & 3 & 150 & 0 \\
\hline Single phialospores & 6 & 300 & 0 \\
\hline
\end{tabular}

* Fifty subcultures were established from each strain for each method of subculture.
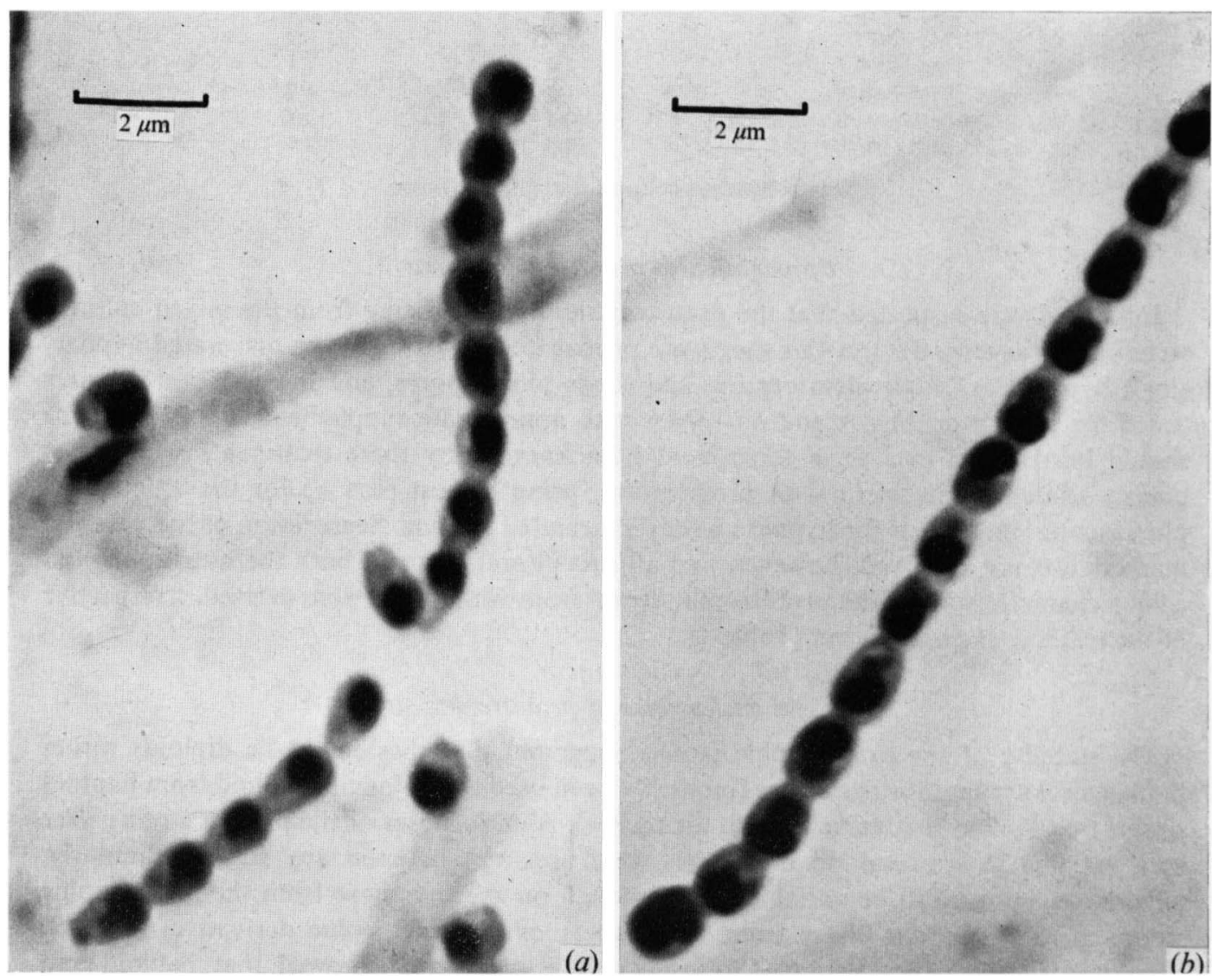

Fig. 2. Phialospore chains of $(a)$ 20-3I and (b) M4+MI7 stained with Giemsa. Note the larger size of the spores and nuclei in $(b)$ than in $(a)$. 
Table 4. Nuclear diameter for original parental strains and derived prototrophic strains of Humicola strain 20-3I

The diameters of 20 phialospore nuclei were measured for each strain from photographic prints of Giemsa-stained preparations.

\begin{tabular}{|c|c|c|c|c|}
\hline \multirow{3}{*}{$\begin{array}{l}\text { Type of strain } \\
\text { Parental }\end{array}$} & \multirow{3}{*}{$\begin{array}{l}\text { Strain no. } \\
20-3 \text { I } \\
20-3 \text { IW } \\
20-3 \text { IB }\end{array}$} & \multicolumn{2}{|c|}{ Nuclear diameter $(\mu \mathrm{m})$} & \multirow{2}{*}{$\begin{array}{l}\text { Mean nuclear } \\
\text { diameter for } \\
\text { strain type }(\mu \mathrm{m})\end{array}$} \\
\hline & & Mean & Range & \\
\hline & & $\begin{array}{l}0.51 \\
0.51 \\
0.51\end{array}$ & $\begin{array}{l}0.46-0.56 \\
0.45-0.55 \\
0.40-0.56\end{array}$ & $0.51 \pm 0.006$ \\
\hline Prototrophic & $\begin{array}{l}\text { M4 + MII } \\
\text { M4 }+ \text { MI6 } \\
\text { M4+MI7 } \\
\text { M4+MI8 } \\
\text { MI6+MI8 } \\
\text { MI7+MI8 }\end{array}$ & $\begin{array}{l}0.64 \\
0.64 \\
0.66 \\
0.63 \\
0.64 \\
0.64\end{array}$ & $\begin{array}{l}0.58-0.71 \\
0.53-0.75 \\
0.61-0.70 \\
0.58-0.71 \\
0.55-0.70 \\
0.61-0.67\end{array}$ & $0.64 \pm 0.004$ \\
\hline
\end{tabular}

were consistently larger than those of the wild-type strains and there was almost no overlap in the distributions (Table 4 and Fig. 2). The ratio of the mean nuclear diameter of prototrophic to wild-type strains is $\mathrm{I} \cdot 25: \mathrm{I}$. This corresponds to a difference in nuclear volume of I.97: I, assuming the nuclei are spherical.

\section{Marker segregation from prototrophic strains}

The comparisons of nuclear size suggested that the prototrophic mycelia arising in mixed cultures of auxotrophs were diploid. To test this, attempts were made to haploidize the suspected heterozygous diploids and obtain segregation of the markers by treatment with FPA (Morpurgo, 196I ; Lhoas, 1961). Prototrophic strains showed increasing inhibition when grown on CMA containing FPA at $60,80,100, \mathrm{I} 20,140$ and $160 \mu \mathrm{g} / \mathrm{ml}$. The wild-type 20-3I and its auxotrophic derivatives were less inhibited at all concentrations. At $\mathrm{I} 40$ and $\mathrm{I} 60 \mu \mathrm{g} \mathrm{FPA} / \mathrm{ml}$ the prototrophic strains, but not the wild-type or auxotrophic mutants, produced more vigorously growing sectors. Twenty-five sectors were isolated from each of the seven prototrophic strains and tested for segregation of colour and auxotrophic markers. With each strain segregation was observed for the two or three markers suspected to be heterozygous (Table 5). Segregation was consistent with a I: I ratio in I5 out of the total of 19 single allele pairs tested (considering each prototrophic strain separately). Three of the four significant deviations resulted from an excess of the wild-type allele. The excess of the mutant allele, $p d x A$, for combination MI6+MI 7 may be explained by the association of $p d x A$ with $\arg A^{+}$, the latter allele being recovered in excess. With the exception of $p d x A$ and $\arg A$ all the markers segregated independently, although the frequencies of recovery of the different genotypes from any one prototrophic strain were often heterogeneous (Table 5).

When FPA-induced segregants, including prototrophs, were reinoculated on to FPA media they possessed the higher tolerance characteristic of 20-3I and its original auxotrophic derivatives and did not produce more vigorous sectors or further marker segregation. Nuclear diameters were measured for eight prototrophic segregants originating from three different prototrophic strains. All had nuclei similar in size to 20-3I and smaller than the prototrophic strains from which they were derived. 


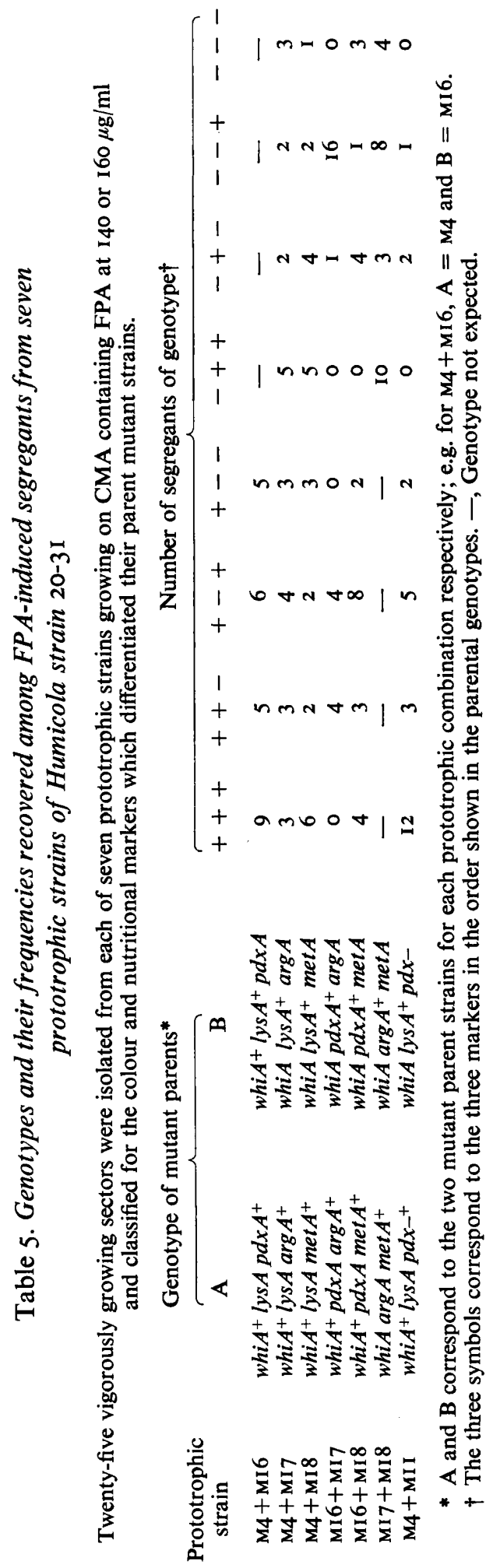




\section{DISCUSSION}

Three lines of evidence indicate that the prototrophic strains which arise directly from mixed cultures of auxotrophic mutants of the Humicola strain 20-3I are heterozygous diploids. Firstly, they remain stably prototrophic and do not segregate when propagated by single protoplasmic units, including uninucleate phialospores. Secondly, they contain nuclei of approximately twice the volume of those of strain 20-3I. Thirdly, they segregate for markers distinguishing their immediate parent auxotrophic strains. Similarly, several related observations indicate that the segregants recovered from FPA treatment of these prototrophic diploid strains are haploid. These are: (i) the known haploidizing effect of FPA on somatic diploids in other fungal species (Morpurgo, I96I; Lhoas, I96I; McCully \& Forbes, 1965); (ii) the simultaneous expression of the various auxotrophic requirements, the latter being invariably determined by recessive alleles; (iii) the failure to induce segregation in first order segregants, including prototrophs, by a second FPA treatment; and (iv) the reduction in nuclear size following FPA treatment. Taken together these observations demonstrate that auxotrophic mutant derivatives of strain 20-3I readily form somatic heterozygous diploids and that the latter can be induced to haploidize by treatment with FPA. Thus, two of the steps of the parasexual cycle (Pontecorvo, 1956; Roper, 1966) have been demonstrated in this strain. It remains to be established whether mitotic crossing-over also occurs.

An unusual feature of the present results is the isolation of heterozygous diploid strains from mixed cultures of auxotrophic mutants without a detectable, intervening, heterokaryotic state. Hyphal anastomosis and heterokaryon formation would appear essential prerequisites for the formation of somatic heterozygous diploids in filamentous fungi (Pontecorvo, 1956; Roper, 1966). Extensive, freely growing heterokaryons, such as are produced by many Aspergillus spp., are not essential for diploid formation however. In Penicillium chrysogenum (Pontecorvo \& Sermonti, 1954) and Cephalosporium acremonium (Nuesch, Treichler \& Liersch, 1973), where heterokaryons grow poorly, diploids arise directly as vigorously growing sectors from the heterokaryotic mycelium. The Humicola strain studied would appear to be an extreme example of this phenomenon, although it is possible that microscopic examination of the mixed cultures would reveal a restricted heterokaryon which is swamped by the vigorous diploid mycelium once this is formed. That diploids can be formed without growth of an intervening heterokaryon is shown by their ready isolation from fused sporidia in Ustilago violacea, where the dikaryons cannot grow in culture (Day \& Jones, 1968).

The demonstration of heterozygous diploid formation and haploidization makes genetic analysis possible in this imperfect soil fungus. The morphological stability of the black/ white diploids and their clear segregation on haploidization into the two parental types with no intermediates suggests that the difference between the spontaneous black and white segregants is under chromosomal control, and that probably only a single gene (whiA) is involved (the possibility of a group of genes on the same linkage group cannot be excluded). This contrasts with the situation found by Hastie (1962) in Verticillium albo-atrum, where a similar, naturally occurring difference in pigmentation appeared to be cytoplasmically determined. Assuming that mitotic crossing-over is rare and that most reassociated genotypes present in the FPA-induced segregants arise through independent chromosome assortment during haploidization, assumptions which hold in other fungal species (Käfer, 196I; McCully \& Forbes, 1965; Lhoas, 1967; Day \& Jones, I968), we can, from the data in Table 5, assign the markers studied to at least four linkage groups as follows: I, whiA; 
II, $\operatorname{lys} A$; III, $p d x A \arg A$; IV, $m e t A$. The remaining marker, $p d x-$, segregated independently of whi $A$ and $l y s A$ and therefore is not in linkage groups I or II. It was not tested against the group III or IV markers or for allelism with $p d x A$, however, and therefore may either be in one of these or represent a fifth linkage group.

The simple genetic differentiation of the black and white strains demonstrates that this very obvious character does not reflect extensive divergence and hence should not be given much weight in any classification. Parasexual genetic analysis may now be applied to other natural character differences and instances of spontaneous variation, in an attempt to determine their origins and judge their potential taxonomic significance. In addition to these indirect aids to classification, investigation of the formation and properties of heterozygous diploids may be of value for the study of homologies in imperfect fungi. For example, Hastie (I973) has shown in Verticillium spp. that recombination is less in interspecific diploids than in intraspecific diploids. However, the widespread occurrence within species of filamentous fungi of simply inherited, vegetative (heterokaryon) incompatibility systems (Caten \& Jinks, I966; Caten, 1972) means that the failure to isolate diploids should be interpreted with caution.

\section{REFERENCES}

Atwood, K. C. \& Norman, A. (1949). On the interpretation of multihit survival curves. Proceedings of the National Academy of Sciences of the United States of America 35, 696-709.

DE Bertoldi, M. (1972). Nuclear distribution in some strains referred to the genus Humicola. Annali di botanica 31, I87-196.

De Bertoldi, M., LePIdi, A. A. \& Nuti, M. P. (1972). Classification of the genus Humicola Traaen. I. Preliminary reports and investigations. Mycopathologia et mycologia applicata 46, 289-304.

DE Bertoldi, M., LePIDI, A. A. \& Nuti, M. P. (1973). Significance of DNA base composition in classification of Humicola and related genera. Transactions of the British Mycological Society 60, 77-85.

DE Bertoldi, M. \& Verona, O. (1970). Micromiceti nuovi o rari per l'Italia isolati de terreni di Sardegna. Agricoltura italiana A 70 (25 N.S.), 349-370.

Caten, C. E. (1972). Heterokaryon incompatibility in imperfect species of Aspergillus. Heredity 26, 299312.

CATEN, C. E. \& Jinks, J. L. (1966). Heterokaryosis: its significance in wild homothallic Ascomycetes and Fungi imperfecti. Transactions of the British Mycological Society 49, 81-93.

Clowes, R. C. \& HAYES, W. (1968). Experiments in Microbial Genetics, p. I9I. Oxford and Edinburgh: Blackwell Scientific Publications.

Clutterbuck, A. J. \& Roper, J. A. (I966). A direct determination of nuclear distribution in heterokaryons of Aspergillus nidulans. Genetical Research 7, 185-194.

DAY, A. W. \& JoNES, J. K. (I968). The production and characteristics of diploids in Ustilago violacea. Genetical Research II, 63-8I.

DAY, A. W. \& JONES, J. K. (1969). Sexual and parasexual analysis of Ustilago violacea. Genetical Research I4, $195-221$.

HASTIE, A. C. (1962). Genetic recombination in the hop-wilt fungus Verticillium albo-atrum. Journal of General Microbiology 27, 373-382.

HaStie, A. C. (1964). The parasexual cycle in Verticillium albo-atrum. Genetical Research 5, 305-3I 5.

HASTIE, A. C. (1973). Hybridization of Verticillium albo-atrum and Verticillium dahliae. Transactions of the British Mycological Society 60, 522-523.

KÄFER, E. (196I). The processes of spontaneous recombination in vegetative nuclei of Aspergillus nidulans. Genetics 46, I58I-1609.

Lepidi, A. A., Nuti, M. P., de Bertoldi, M. \& Santulli, M. (1972). Classification of the genus Humicola Traaen. II. The DNA base composition of some strains within the genus. Mycopathologia et mycologia applicata 47, I53-I 59.

LhOAS, P. (196I). Mitotic haploidization by treatment of Aspergillus niger diploids with p-fluorophenylalanine. Nature, London r9o, 744.

LhoAs, P. (1967). Genetic analysis by means of the parasexual cycle in Aspergillus niger. Genetical Research Io, 45-6r. 
MCCulLy, K. S. \& Forbes, E. (1965). The use of $p$-fluorophenylalanine with 'master strains' of Aspergillus nidulans for assigning genes to linkage groups. Genetical Research 6, 352-359.

MORPURGO, G. (196I). Somatic segregation induced by $p$-fluorophenylalanine. Aspergillus Newsletter 2, I0.

Nuesch, J., Treichler, H. J. \& Liersch, M. (1973). The biosynthesis of cephalosporin C. In Genetics of Industrial Microorganisms, vol. 2, pp. 309-334. Edited by Z. Vanek, Z. Hostalek and J. Cudlin. Amsterdam, London and New York: Elsevier.

Pontecorvo, G. (1956). The parasexual cycle in fungi. Annual Review of Microbiology 10, 393-400.

PonteCorvo, G. \& KäFER, E. (1958). Genetic analysis by means of mitotic recombination. Advances in Genetics 9, 7I-104.

Pontecorvo, G. \& Sermonti, G. (1954). Parasexual recombination in Penicillium chrysogenum. Journal of General Microbiology II, 94-104.

Pontecorvo, G., Roper. J. A. Hemmons, L. M., Macdonald, K. D. \& Bufton, A. W. J. (1953). The genetics of Aspergillus nidulans. Advances in Genetics 5, 141-238.

RIDDEL, R. W. (1950). Permanent stained mycological preparations obtained by slide culture. Mycologia 42 , $265-270$.

RoBinow, C. F. \& CATEN, C. E. (1969). Mitosis in Aspergillus nidulans. Journal of Cell Science 5, 403-43I.

RoPER, J. A. (1966). Mechanisms of inheritance. III. The parasexual cycle. In The Fungi, an Advanced Treatise, vol. 2, pp. 589-617. Edited by G. C. Ainsworth and A. S. Sussman. New York and London: Academic Press.

Tintine, R. D. \& MCNeil, B. H. (1969). Parasexuality in plant pathogenic fungi. Annual Review of Phytopathology 7, 147-170. 